\title{
Main Properties of Sands Hydrophobized by Alkoxysilane Emulsions
}

\author{
Marek WOJCIECHOWSKI, Patrycja BARYŁA, \\ and Marek LEFIK
}
Łódź University of Technology, Department of Civil Engineering, Architecture and Environmental Engineering, Łódź, Poland e-mails: mwojc@p.lodz.pl, patrycja.baryla@p.lodz.pl, marek.lefik@p.lodz.pl (corresponding author)

\begin{abstract}
The results of laboratory tests and geotechnical view on sands hydrophobized by alkoxysilane emulsions are presented. For the soils subjected to this process, very low permeability and no capillary elevation was observed. Laboratory tests also indicate that other physical and mechanical properties of hydrophobized sands remain nearly untouched, i.e., the considered hydrophobisation process does not reduce the strength of soils. Properly composed alkoxysilane emulsions can also solidify in pores to produce a stabilizing silicate binder. The filtration barriers in ground and soil stabilization are thus considered as possible applications of the hydrophobized soils. The process of treatment of granular soils with alkoxysilanes is neutral for the environment and the cost of implementation of the method is relatively low.
\end{abstract}

Key words: hydrophobized soil, hydrophobization in geotechnical engineering.

\section{INTRODUCTION}

In civil engineering hydrophobization is defined as a process aimed at increasing the resistance against the penetration of water through surfaces existing on newly constructed buildings. These treatments involve the impregnation of masonry, plaster, or roofs by means of emulsions based on 
silanes and siloxanes. Potential use of hydrophobizing means in building industry and in particular in geotechnics is still much wider. Hydrophobized mineral soil (like sand) characterized by reduced capillary rise of water and low permeability can be used, e.g., as sand bed or backfill for foundations, walls, floors, and underground wall facilities. Modified sand reduces the risk of wetting and moisture penetration. Hydrophobization carried out in situ (usually through injections of hydrophobizing means into the sand layer) opens also the way for making temporary and permanent impermeable barriers in the ground in road and bridge building industry. It secures against spreading of pollutants in the ground medium and may be used to increase leakproofness and strengthen the barrages and flood banks even if the mechanical parameters of soil remain unaltered. The properly composed alkoxysilane emulsions can also solidify in pores to a stabilizing silicate binder. Sufficiently low permeability and negative capillary pressure observed in pores of the soil subjected to the hydrophobization process, as well as neutral environment influence and relatively low cost of implementation are the key conditions of the effective implementation of the applications listed above. The legitimacy of hydrophobized sands is confirmed best if it would be proved that hydrophobization process does not have a negative influence on their mechanical strength properties and compactability. Three independent variables govern the problem of the effectiveness of the impermeabilization of granular media. These are: the chemical composition of the emulsion, the granulometric curve of the sand, and the quantity of the emulsion related to the mass of the skeleton. The analysis of the granular composition at the micro level and the micro-mechanical behaviour are fundamental for macro properties of the hydrophobized material. At this point of the research we performed laboratory test for a single medium sand (MSa) against couple of different emulsions measuring the permeability coefficient and other physical quantities. In further analysis, an influence of the granular composition of sand on the effectiveness of the hydrophobization process has to be investigated. Also the positive impact of the emulsion solidification on mechanical properties like stiffness parameters, cohesion and angle of internal friction will be accounted for. At the moment there are no evidences that the strength of soil will be improved, although it is quite sure that mechanical properties are not deteriorated by the hydrophobization process. In the following we discuss shortly the hydrophobization phenomenon, then the laboratory test results are presented and the application examples are shortly discussed.

\section{HYDROPHOBIZATION PHENOMENON}

Wettability of the surface is described by the parameter called contact angle, measured through the liquid in the place where a liquid/gas interface meets a solid surface. This is illustrated in Fig. 1. The contact angle depends not 


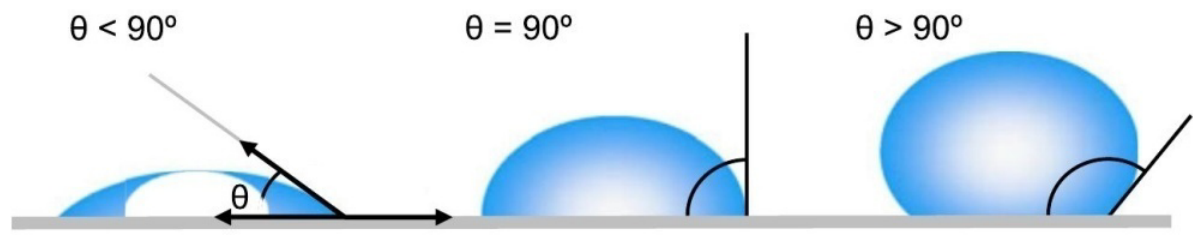

Fig. 1. Contact angle (Yuan and Lee 2013).

only on the chemical properties of the solids, but also on the properties of the liquid (which is usually water in soil mechanics), temperature and pressures in liquid and gas. All these factors influence the thermodynamic equilibrium state at the contact of the three phases in the soil. Contact angle in the static system: surface of soil particle-water-air is lower than $90^{\circ}$ in typical cases. This means that the grain surfaces are "wettable" (hydrofilic). On the macroscopic level this is manifested by the capillary elevation in pores, because of the positive capillary pressure:

$$
p_{k}=\frac{2 \sigma_{\mathrm{wa}} \cos \theta}{r} .
$$

In the above equation, $\sigma_{\text {wa }}$ is the water-air surface tension, $r$ is the radius of the capillary, and $\theta$ is the contact angle. If $\theta<90^{\circ}$ then positive pressure and movement of water in the direction of air is observed. The chemical processes associated with alkoxysilane hydrophobization (the details can be found in Stańczyk et al. 2012) modify characteristics of the surfaces of the mineral grains. The increase of the contact angles to the values greater than $90^{\circ}$ is observed and the surfaces become "non-wettable" (hydrophobic). This change (performed at the micro level) has a consequence of the non-wettability of the soil at the macro scale as well (see Fig. 2).

(a)

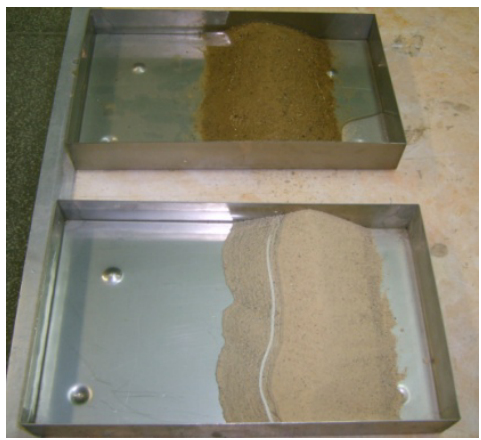

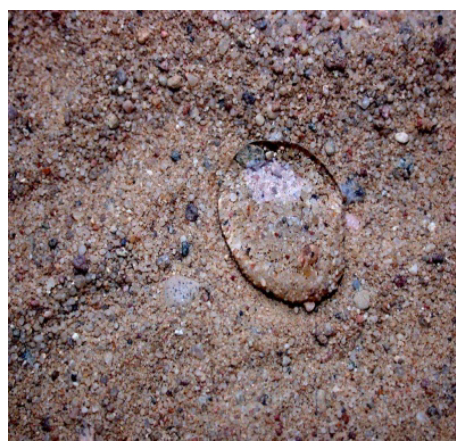

(b)

Fig. 2. Macroscopic behavior of the hydrophobized sand: (a) permeable and impermeable sand barrier, and (b) single drop of water on the soil. 
The hydrolysis process, the mutual condensation of the functional groups, and the condensation of mineral components with Si-OH groups lead to formation of binding network analogous to those in silica itself. As a result, the hydrophobic layer around each soil grain is formed. The strength of binding between this layer and silica is the same as between silica groups in a sand grain. The hydrophobic film could be removed only by attrition with a very high friction force or by using a solvent able to dissolve sand.

The hydrophobic binding starts to form right after adding the alkoxysilan emulsion with no presence of any catalyst. The hydrolysis process can proceed in atmospheric conditions (the bindings network is formed during drying - it takes about two weeks). In laboratory conditions, however, the process is being accelerated by warming the sample in the temperature of $50-55^{\circ} \mathrm{C}$ (the sample is hydrophobic after few days). This emulsion is efficient for all materials that have "free" OH groups. In the 1970s, previous tests under hydrophobization of porous materials were conducted in our research center. Many types of materials, including calcareous stones, were tested. Test results were very promising - the samples remain hydrophobized to this day, after more than 25 years.

Capillary elevation should not be observed here, because of the negative capillary pressure. Moreover, assuming there is water in the pores of the hydrophobized sand, the "air suction" should be observed which "pushes out" water from the soil. In reality, the swelling behavior is more probable, i.e., the pressure will tend to increase the radius of the capillaries (increasing porosity). The stabilizing effects of the surface tension forces in unsaturated soils will not be present any more (see Fig. 3) and this can influence mechanical properties of the hydrophobized sands slightly (for dry sands the parameters should be preserved). On the other hand, the material will be very hard to be saturated and it will present decreased permeability for water.

(a)
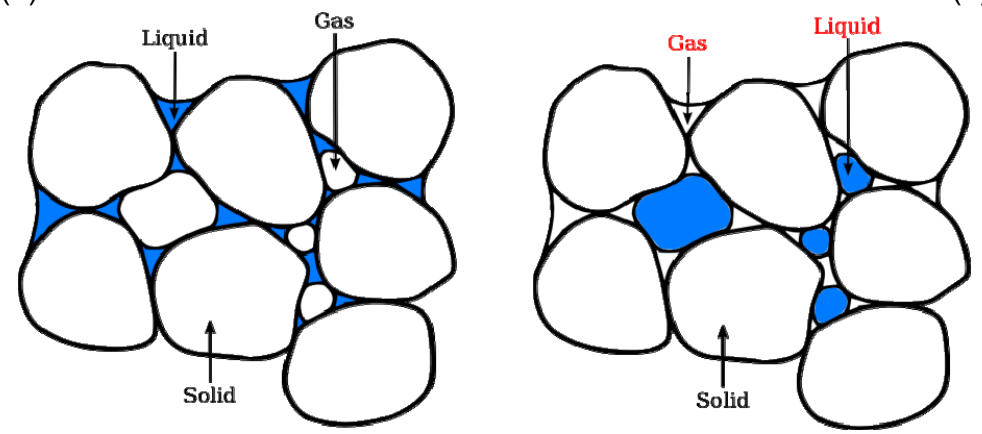

Fig. 3. Partially saturated soils: (a) not hydrophobized, and (b) hydrophobized. 


\section{LABORATORY TESTING}

\subsection{Sample preparation}

Tests were performed for medium sands with similar particle size distribution (see Fig. 4), mixed with several types of hydrophobizing emulsions (see Table 1). Sample preparation was performed in laboratory conditions with the following procedure:

$\checkmark$ dry medium sand was combined with alkoxysilane emulsion in the mass ratio 9:1;

a mechanical mixer with auger cap was used to homogenise the ingredients (10 minutes of mixing), then the sample was moved to a securely closed container and shaken a couple of times a day;

$\checkmark$ wet modified sand was stored in closed container by 7 days, then by 3 days the container was kept open;

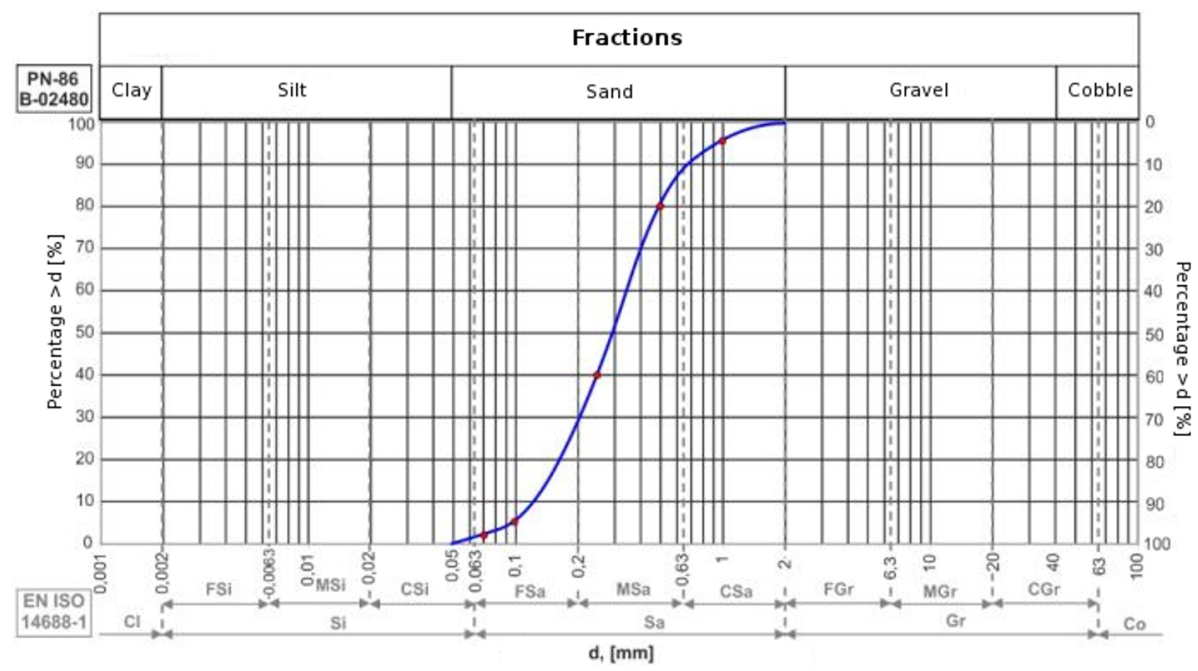

Fig. 4. Granular sieve curve of the considered medium sand.

Table 1

Alkoxysilan emulsions compositions

\begin{tabular}{|c|c|c|c|c|}
\hline Emulsion & Silane type & $\begin{array}{c}\text { Silane mass } \\
{[\mathrm{g}]}\end{array}$ & $\begin{array}{c}\text { Surface active } \\
\text { substance } \\
{[\mathrm{g}]}\end{array}$ & $\begin{array}{c}\text { Emulsifier } \\
{[\mathrm{g}]}\end{array}$ \\
\hline E1 & $\mathrm{MeSi}(\mathrm{OMe})_{3}$ & 80 & 2.0 & 0.72 \\
E2 & $\mathrm{MeSi}(\mathrm{OMe})_{3}$ & 80 & 0.4 & 0.36 \\
E3 & $\mathrm{MeSi}(\mathrm{OMe})_{3}$ & 40 & 0.4 & 0.36 \\
E4 & $\mathrm{MeSi}(\mathrm{OMe})_{3}$ & 40 & 0.4 & 0.36 \\
\hline
\end{tabular}


$\square$ in order to speed up the silanolate condensation, the sand was kept at a temperature of $50-55^{\circ} \mathrm{C}$ : at the beginning in the closed container by 10 hours and the next 10 hours in the open container.

This procedure assured no active substance (alkiloalkoxysilane) is left in the pores and the full possible hydrophobization effect is obtained.

\subsection{Permeability and capillary elevation}

Permeability of the natural sands was tested in standard "ZWK-2" apparatus. For the hydrophobized sands, a triaxial cell has to be used, because of relatively large pressures needed to saturate the soil and induce water flow. Basics of the technique of permeability testing in the triaxial cell can be found in (Carpenter and Stephenson 1986). In this research we used the following procedure:

$\checkmark$ preparation of samples from a dry sand (diameter of $38 \mathrm{~mm}$, height of $c a .70 \mathrm{~m}$ );

- flushing, i.e. application of small pressure in the triaxial cell (10$20 \mathrm{kPa}$ ) and initiation of the flow of water through sample applying slight back pressure and leaving drain valve open; at this stage the macro pores near the latex membrane (which is hydrofilic) are filled with water;

$\square$ saturation - at this stage the air which remains in pores is dissolved in water (there is no flow through sample); the quality of saturation is measured by the Skempton parameter:

$$
B=\frac{\Delta u}{\Delta \sigma},
$$

where $\Delta u$ is the increase of pore pressure associated with the increase of pressure in triaxial cell $\Delta \sigma$ (these values should be as close as possible, i.e, $B$ should be near to 1 ); every check of $B$ parameter is proceeded by increase of the back pressure which tries to saturate the sample (effective stress was kept on the same level of $c a .50 \mathrm{kPa}$ ); it turns out that very high pressures, of the range of $1000 \mathrm{kPa}$ and more, are needed to saturate hydrophobized samples;

$\square$ permeability testing - the pressure gradient between top and bottom of the sample was set up in the range of 2 to $90 \mathrm{kPa}$ (hydraulic gradient between 3 and 100), the amounts of flowing water were measured and the steady flow filtration coefficient was calculated.

Permeability test results are listed in Table 2 . The lowest values of the filtration coefficient were obtained for sands modified with E2 and E3 emulsions. The difference in comparison to natural sands is about four orders of magnitude. 
Table 2

Filtration coefficient ranges

for natural and hydrophobized sands

\begin{tabular}{|c|c|}
\hline Sample type & $\begin{array}{c}\text { Filtration coefficient }(T=21 \mathrm{C}) \\
{[\mathrm{m} / \mathrm{s}]}\end{array}$ \\
\hline $\mathrm{MSa}$ & $1.07 \mathrm{e}-4 \div 4.85 \mathrm{e}-5$ \\
$\mathrm{MSa}+\mathrm{E} 1$ & $6.63 \mathrm{E}-7 \div 3.23 \mathrm{E}-7$ \\
$\mathrm{MSa}+\mathrm{E} 2$ & $2.10 \mathrm{E}-8 \div 5.37 \mathrm{E}-9$ \\
$\mathrm{MSa}+\mathrm{E} 3$ & $4.38 \mathrm{E}-8 \div 4.53 \mathrm{E}-9$ \\
$\mathrm{MSa}+\mathrm{E} 4$ & $4.56 \mathrm{E}-7 \div 8.32 \mathrm{E}-8$ \\
\hline
\end{tabular}

Table 3

Capillary elevation for natural and hydrophobized sands

\begin{tabular}{|c|c|}
\hline Sample type & $\begin{array}{c}\text { Capillary elevation }(t=400 \mathrm{~min}) \\
{[\mathrm{cm}]}\end{array}$ \\
\hline $\mathrm{MSa}$ & 5.3 \\
$\mathrm{MSa}+\mathrm{E} 1$ & 1.3 \\
$\mathrm{MSa}+\mathrm{E} 2$ & 0 \\
$\mathrm{MSa}+\mathrm{E} 3$ & 0 \\
$\mathrm{MSa}+\mathrm{E} 4$ & 1.6 \\
\hline
\end{tabular}

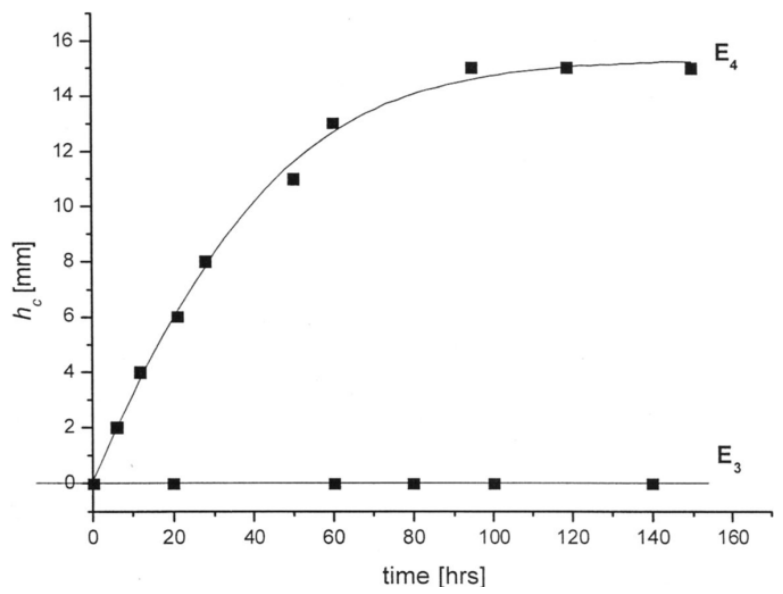

Fig. 5. Capillary elevation test results for natural and hydrophobized sands.

The capillary elevation was tested be means of standard apparatus for active capillarity measurement. Test results are presented in Fig. 5 and in Table 3. Similarly as for permeability, the most promising results (no capillary rise at all) were obtained for emulsions E2 and E3. 


\subsection{Other hydrophobized soil parameters}

For natural sand and for sand modified with E2 emulsion, also other parameters were determined. Tests were performed with standard procedures according to Polish Standard PN-88/B-04481. The results are presented in Table 4.

Table 4

Some physical parameters for natural and hydrophobized sands

\begin{tabular}{|c|c|c|c|c|}
\hline $\begin{array}{c}\text { Sample } \\
\text { type }\end{array}$ & $\begin{array}{c}\text { Friction angle } \\
{\left[{ }^{\circ}\right]}\end{array}$ & $\begin{array}{c}\text { Specific density } \\
{\left[\mathrm{g} / \mathrm{cm}^{3}\right]}\end{array}$ & $\begin{array}{c}\text { Min. bulk density } \\
{\left[\mathrm{g} / \mathrm{cm}^{3}\right]}\end{array}$ & $\begin{array}{c}\text { Max. bulk density } \\
{\left[\mathrm{g} / \mathrm{cm}^{3}\right]}\end{array}$ \\
\hline $\mathrm{MSa}$ & 37.3 & 2.65 & 1.50 & 1.75 \\
$\mathrm{MSa}+\mathrm{E} 2$ & 37.1 & 2.65 & 1.51 & 1.76 \\
\hline
\end{tabular}

Comparing test results obtained for natural and hydrophobized sands it is noted that hydrophobization process does not influence significantly either strength of the soil or specific and dry bulk densities. Tests have shown that these properties remain almost the same after hydrophobization process. It should also be mentioned that because of the non-wettability of the sand grains, it is unlikely that the presence of water in pores will influence positively the maximum bulk density during compaction process (as it is observed for natural soils). Thus, it can be assumed that hydrophobized sand will be best compacted being dry and the maximum bulk density determined for dry modified material describes sufficiently also its compactability.

\section{APPLICATION PROSPECTS}

In geotechnical applications, the hydrophobization of soils can be performed in the following two ways:

$\square$ in the preproduction process with controlled hydrophobizing conditions - such prepared material can be built in the geotechnical structures with a variety of methods, depending on the specific application;

口 in situ hydrophobization - via methods like low and high pressure injection of the alkoxysilane emulsion, deep soil mixing, etc.

Pre-produced hydrophobized sand can be used as bed or backfill for foundations, walls, floors, and underground walls facilities. It can be used also, for example, in strengthening embankments (see, e.g., Figs. 6 and 7a).

On the other hand, the in situ hydrophobization can be well suited to perform vertical filtration barriers and soil stabilization and strengthening (Fig. 7b). Both methods need to be investigated in details in technical or half-technical scale (this is one of the priority scopes of our research). Additionally it have to be remembered that the in situ application of alkoxysilane 


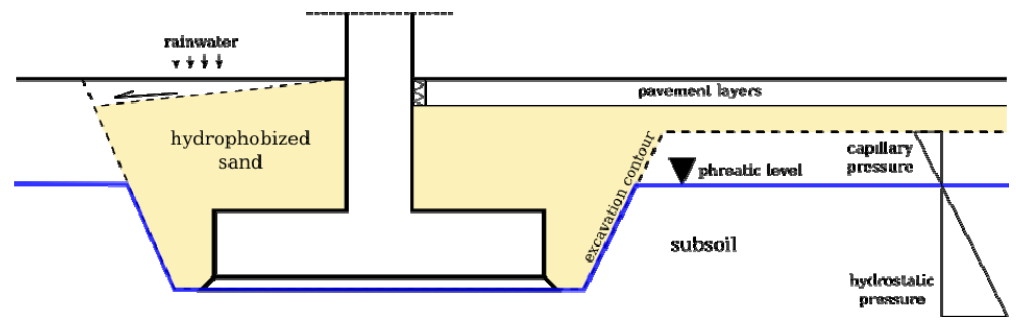

Fig. 6. Hydrophobized sand as a ground water protection for a building.

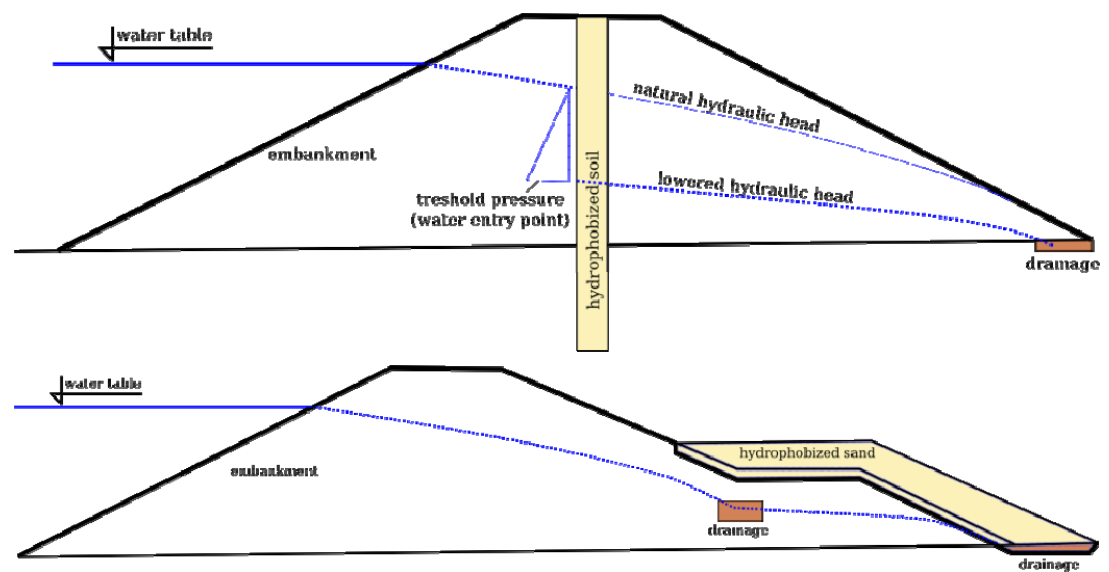

(a)

(b)

Fig. 7. Applications of hydrophobized sand: (a) vertical filtration barrier in the embankment; in this case also the soil strengthening can be achieved (solidification of alkoxisilane emulsion in pores); (b) heightened and expanded embankment buttress; hydrophobized sand protects against the hydraulic perforation and infiltration of rainwater.

emulsions have to be treated as any other soil strengthening method, i.e., it must be always adjusted to the ground conditions and other particular requirements.

\section{CONCLUSIONS}

An important advantage of using alkoxisilane hydrophobization is the completely ecological nature of the process. The economical method of obtaining alkoxysilanes and their aqueous mixtures, as well as their composition, are currently the subject of patent application (Stańczyk et al. 2012). Laboratory tests performed showed much lower permeability after hydrophobization for medium sands. We believe that for fine and silty sands the effect of the hydrophobization will be even better. These types of soils have got in fact lower initial permeability coefficient and larger specific surface area. Furthermore, in addition to research of capillary rise and permeability, the per- 
foration pressure (pressure that initiates the flow in hydrophobized soil) will also be studied. Knowledge about this parameter is necessary for practical applications of the modified sands. The usage prospects of hydrophobized soils in geotechnics are quite broad, especially if we take into account that the modification introduced does not influence significantly the compactability, stiffness, and strength parameters of dry sands. However, there is still a need to investigate mechanics of the saturated and partially saturated soils consisted in the non-wettable minerals. The relations for permeability with respect to the granulometric curve of the soil also need to be derived. The usual empirical relations (see for example Revil and Cathles 1999) are not applicable here. For this purpose a lot of experimental data have to be generated and the artificial neural network approach is planned to be used (Lefik and Wojciechowski 2005).

Acknowledgments. The scientific research reported here has been carried out as a part of the Project "Innovative recourses and effective methods of safety improvement and durability of buildings and transport infrastructure in the sustainable development" at the Technical University of Lódź, Poland, financed by the European Fund of Regional Development based on the Operational Program of the Innovative Economy.

The authors would like to thank Professor W.A. Stańczyk and his team for the invitation to joint research on the application of his method of hydrophobization to granular soils.

\section{References}

Carpenter, G.W., and R.W. Stephenson (1986), Permeability testing in the triaxial cell, Geotech. Test. J. 9, 1, 3-9, DOI: 10.1520/GTJ10605J.

Revil, A., and L.M. Cathles (1999), Permeability of shaly sands, Water Resour. Res. 35, 3, 651-662, DOI: 10.1029/98WR02700.

Lefik, M., and M. Wojciechowski (2005), Artificial Neural Network as a numerical form of effective constitutive law for composites with parameterized and hierarchical microstructure, Comput. Assis. Mech. Eng. Sci. 12, 2-3, 183-194.

Stańczyk, W.A., T. Ganicz, J. Kurjata, and A. Szelagg (2012), Sposób katalitycznej depolimeryzacji silikonów, Patent Application PL, P-398868 (in Polish).

Yuan, Y., and T.R. Lee (2013), Contact angle and wetting properties. In: G. Bracco and B. Holst (eds.), Surface Science Techniques, Springer Series in Surface Sciences, Vol. 51, Springer, Berlin Heidelberg, 3-34, DOI: 10.1007/978-3642-34243-1_1.

Received 23 September 2013

Received in revised form 30 April 2014

Accepted 7 May 2014 